\title{
Mikroenkapsulasi Asap Cair Tempurung Kelapa Menggunakan Variasi Total Padatan Terlarut
}

\author{
Nurul Azizah Choiriyah ${ }^{1 *}$, Nur Arifah Qurota A'yunin ${ }^{2}$, Hesti Ayuningtyas Pangastuti ${ }^{3}$, dan \\ Yohanna Prasetio ${ }^{1}$ \\ 1Program studi Seni Kuliner, Akademi Kuliner dan Patiseri OTTIMMO Internasional \\ ${ }^{2}$ Program studi Agroteknologi, Universitas Siliwangi \\ ${ }^{3}$ Program Studi Teknologi Pangan, Institut Teknologi Sumatera \\ *Alamat korespondensi: nurul@ottimmo.ac.id
}

\begin{tabular}{lrc}
\hline \multicolumn{2}{c}{ INFO ARTIKEL } & ABSTRACT/ABSTRAK \\
\hline Diterima: & $20-10-2021$ & \\
Direvisi: & $04-01-2022$ & Microencapsulation of Coconut Shell Liquid Smoke Using Variations in \\
Dipublikasi:23-01-2022 & Total Soluble Solids
\end{tabular}

Keywords:

Maltodextrin,

Microencapsulation,

Organic acid, Phenol

Kata Kunci:

Maltodekstrin,

Mikroenkapsulasi, Asam

organik, Fenol
Liquid smoke is a product of the carbonization process of wood at high temperatures in the absence of oxygen. The content of bioactive compounds in liquid smoke consists of phenolic compounds and organic acids that have antimicrobial and antioxidant abilities. Bioactive compounds are easily oxidized or very unstable to heat and metals. Microencapsulation technology can prevent the oxidation process. The purpose of this study was to evaluate the effect of total soluble solid on phenol content, organic acid content and carbonyl content of liquid smoke microcapsules. The study used one factor, the percentage of Total Soluble Solids (TPT 15\%, TPT 20\%, TPT 25\%) as treatment. The process of microencapsulation of liquid smoke was done by adding maltodextrin into liquid smoke until it reached the percentage of Total Soluble Solids according to the variable. The change of the dispersion solution into micro-sized powder was carried out by spray drying using an inlet temperature of $130^{\circ} \mathrm{C}$. The highest phenol content was liquid smoke microcapsules with TPT 15\%. The addition of maltodextrin as encapsulant did not affect the total carbonyl content of liquid smoke microcapsules. The addition of maltodextrin can increase the total acid content in liquid smoke microcapsules. The best liquid smoke encapsulation process can be carried out using maltodextrin coating material (TPT 15\%) because it has the highest total phenol content which contributed to its antioxidant and antimicrobial properties.

Asap cair merupakan suatu bahan hasil dari proses karbonisasi kayu pada suhu tinggi tanpa adanya kehadiran oksigen. Kandungan senyawa bioaktif asap cair terdiri dari senyawa fenol dan asam organik yang memiliki kemampuan sebagai antimikroba dan antioksidan. Senyawa bioaktif mudah mengalami oksidasi atau sangat tidak stabil terhadap panas dan logam. Teknologi mikroenkaspulasi mencegah terjadinya proses oksidasi. Tujuan penelitian ini adalah mengetahui pengaruh perbedaan total padatan terlarut dari penambahan bahan penyalut maltodekstrin terhadap kadar fenol, kadar asam dan kadar karbonil mikrokapsul asap cair dari tempurung kelapa. Percobaan menggunakan satu faktor, yaitu perbedaan persentase Total Padatan Terlarut (TPT) 15\%, 20\%, dan 25\% sebagai perlakuan. Proses mikroenkapsulasi asap cair dengan melakukan pencampuran maltodekstrin pada larutan asap cair hingga mencapai persentase Total Padatan Terlarut sesuai perlakuan. 
Perubahan larutan dispersi menjadi bubuk berukuran mikro dilakukan dengan spray drying menggunakan suhu inlet $130^{\circ} \mathrm{C}$. Kadar fenol tertinggi adalah mikrokapsul asap cair dengan enkapsulan maltodekstrin sampai denganTPT 15\%. Penambahan maltodekstrin sebagai enkapsulan tidak berpengaruh pada kadar total karbonil mikrokapsul asap cair. Penambahan maltodekstrin dapat meningkatkan kadar total asam pada mikrokapsul asap cair. Proses enkapsulasi asap cair terbaik dapat dilakukan menggunakan bahan penyalut maltodekstrin dengan TPT 15\% karena memiliki kadar total fenol tertinggi yang berkontribusi terhadap sifat antioksidan dan antimikroba.

\section{PENDAHULUAN}

Pengasapan merupakan teknik pengawetan yang sudah lama digunakan dalam teknologi pangan. Dengan perkembangan zaman, metode pengasapan yang dirasa membutuhkan proses panjang dan tidak praktis maka dibutuhkan solusi seperti teknologi asap cair. Asap cair juga dikenal sebagai cuka kayu (wood vinegar) yaitu suatu bahan hasil dari proses karbonisasi kayu pada suhu tinggi tanpa adanya kehadiran oksigen. Asap cair juga memiliki kelebihan dibanding pengasapan tradisional yaitu tidak mengandung senyawa polycyclic aromatic hydrocarbon (PAH) (Widiastuti dkk., 2019).

Asap cair dapat dibuat dari tempurung kelapa, kayu eucalyptus, bambu, kayu pohon akasia dan lain sebagainya (Oramahi \& Diba, 2013). Asap cair dinilai cocok dikembangkan pada industri pengasapan pangan, seperti pada produk daging, keju dan beberapa produk perikanan (Sokamte-Tegang et al., 2020). Perbedaan jenis kayu akan menghasilkan jenis aroma yang berbeda pada asap cair.

Kandungan senyawa bioaktif asap cair terdiri dari senyawa fenol dan asam organik yang memiliki kemampuan sebagai antimikroba dan antioksidan (Desvita et al., 2020). Menurut (Widiastuti dkk., 2019), dalam asap cair juga ditemukan senyawa karbonil yang bertindak sebagai pengawet. Menurut Poluakan dkk. (2015), asap cair dapat menghambat pertumbuhan bakteri Salmonella dan Eschericia coli pada produk bakso ikan. Dalam bidang pertanian, senyawa fenol dan asam pada asap cair efektif dalam menghambat pertumbuhan Fusarium oxysporum yang menyebabkan penyakit layu pada tanaman tomat (Mugiastuti \& Manan, 2009), cendawan Colletotrichum capsici pada tanaman dan buah cabai (Zuanif \& Despita, 2019), penyakit bulai pada tanaman jagung (Kusumawati \& Zuhro, 2019).

Senyawa bioaktif mudah mengalami oksidasi atau sangat tidak stabil terhadap panas dan logam. Teknologi mikroenkaspulasi mencegah terjadinya proses oksidasi. Mikroenkapsulasi yaitu proses mengubah benda cair menjadi bubuk dalam ukuran mikro (mikrokapsul) (Naufalin \& Rukmini, 2016). Beberapa kelebihan dari produk mikrokapsul yaitu perlindungan senyawa aktif bahan pangan selama penyimpanan, memudahkan dalam pendistribusian, immobilitas senyawa aktif pada sistem proses pangan, menutupi rasa yang tidak enak (off-taste) dan untuk control release (Petzold et al., 2014). Pada proses mikroenkapsulasi, bahan penyalut melindungi inti bahan yang dikapsulkan. Bahan penyalut yang umum digunakan dalam enkapsulasi adalah maltodektrin yang terbukti secara efektif mampu melindungi senyawa bioaktif seperti fenol (Yudhistira \& Choiriyah, 2021). Maltodekstrin merupakan polisakarida yang memiliki daya kemampuan tinggi dalam mengikat senyawa fenol (Savikin et al., 2013).

Penelitian terdahulu mengkaji pembuatan mikrokapsul asap cair menggunakan dekstrin 3\% (Ariestya et al., 2016). Selanjutnya Syah et al. (2015) mengkaji pembuatan mikrokapsul asap cair menggunakan maltodekstrin dari beras merah dengan konsentrasi 20\%, 25\%, dan 30\%. Hasilnya menunjukkan bahwa semakin tinggi konsentrasi bahan penyalut yang digunakan, hasil dan efisiensi enkapsulasi juga meningkat. Tujuan penelitian ini adalah mengetahui pengaruh perbedaan total padatan terlarut dari penambahan maltodekstrin terhadap kadar fenol, kadar asam dan kadar karbonil mikrokapsul asap cair dari tempurung kelapa.

\section{BAHAN DAN METODE}

\section{Preparasi Tempurung Kelapa}

Tempurung kelapa yang digunakan harus bersih dari daging dan sabut kelapa. Tempurung kelapa kemudian dilakukan pengeringan di bawah sinar matahari selama 3 hari. Selanjutnyaan dilakukan pengecilan ukuran dengan ukuran $5 \mathrm{~cm}$ x $5 \mathrm{~cm}$ untuk mempercepat waktu pirolisis. 


\section{Pembuatan Asap Cair}

Pembuatan asap cair sebagai berikut tempurung kelapa dilakukan pirolisis 3 jam suhu $400^{\circ} \mathrm{C}$ (Darmadji, 2002). Asap cair masih berupa campuran asap cair dan tar. Asap cair Grade 1 (yang mengandung tar) ini lalu diendapkan 2 hari sehingga racun tar memisah dan mengendap (Talib dkk., 2020). Asap cair kemudian didestilasi hingga menghasilkan asap cair yang lebih murni dan disebut asap cair Grade 2.

\section{Pembuatan Mikrokapsul Asap Cair}

Proses mikroenkapsulasi asap cair dilakukan sebagai berikut: asap cair ditambahkan maltodekstrin sedikit demi sedikit (setiap $5 \mathrm{~g}$ ) dengan stirrer hingga mencapai persentase Total Padatan Terlarut (\% TPT) sesuai perlakuan. Perubahan larutan dispersi menjadi bubuk berukuran mikro dilakukan dengan spray drying menggunakan suhu inlet $130^{\circ} \mathrm{C}$ (Kurniasih dkk., 2016). Perlakuan (variabel bebas) pada penelitian ini total padatan terlarut $15 \%$, 20\%, dan $25 \%$ dari penambahan bahan penyalut maltodekstrin.

\section{Pengamatan}

Sampel mikrokapsul asap cair yang diperoleh dari tiga taraf faktor perlakuan total padatan terlarut $15 \%$, $20 \%$, dan $25 \%$ dari penambahan bahan penyalut maltodekstrin kemudian disimpan dalam kemasan alumunium foil suhu $20^{\circ} \mathrm{C}$ sampai dilakukan analisis laboratorium. Parameter yang diuji pada penelitian ini yaitu kadar total fenol, total asam dan total karbonil (Saloko et al., 2013).

Prosedur pengujian total fenol sebagai berikut $1 \mathrm{~g}$ mikrokapsul asap cair diencerkan dengan penambahan akuades sampai $25 \mathrm{ml}$. Sebanyak $1 \mathrm{ml}$ dari pengenceran tersebut diambil dan diencerkan kembali sampai dengan $100 \mathrm{ml}$ (fp=2500x). Hasil pengenceran diambil $1 \mathrm{ml}$ dan ditambah larutan $5 \mathrm{ml} \mathrm{Na} 2 \mathrm{CO}_{3}$ alkali $2 \%$ dan dibiarkan selama 10 menit. Kemudian ditambahkan larutan folin ciopcalteau sebanyak $0,5 \mathrm{ml}$ untuk kemudian divortex dan dibiarkan selama 30 menit. Absorbansi diukur pada panjang gelombang $750 \mathrm{~nm}$. Konsentrasi larutan fenolat dihitung berdasarkan kurva standar yang diperoleh dari larutan fenol murni. Kadar fenol dihitung menggunakan rumus:

$$
\% \text { fenol }=\frac{\mathrm{X} \times \mathrm{fp}}{\mathrm{mg} \text { sampel }} \times 100 \%
$$

Prosedur pengujian total asam dilakukan dengan menimbang sebanyak $1 \mathrm{~g}$ mikrokapsul asap cair ditambahkan $100 \mathrm{ml}$ aquades kemudian dicampur hingga homogen. Larutan terakhir diambil $1 \mathrm{ml}$ dan diencerkan menjadi $100 \mathrm{ml}$. Setelah homogen, ditambahkan 3 tetes indikator PP. Kemudian, larutan dititrasi dengan $\mathrm{NaOH}$ $0,1 \mathrm{~N}$ hingga berwarna merah muda. Persentase asam asetat kemudian dihitung dengan rumus:

$$
\% \text { asetat }=\frac{\mathrm{ml} \mathrm{NaOH} \times \mathrm{N} \mathrm{NaOH} \times \mathrm{BM} \text { asam asetat } \mathrm{xfp} \times 100}{\mathrm{mg} \text { sampel }}
$$

Pengukuran total karbonil dilakukan dengan mengencerkan $1 \mathrm{ml}$ asap cair dengan ditambahkan akuades sampai volume $25 \mathrm{ml}$. Larutan diambil $1 \mathrm{ml}$ dan diencerkan kembali hingga mencapai volume 100 $\mathrm{ml}(\mathrm{fp}=2500 \mathrm{x})$. Hasil pengenceran diambil $1 \mathrm{~mL}$ dan dicampur dengan $1 \mathrm{~mL}$ 2,4-dinitrophenyl hidrazine dan 1 tetes HCL pekat. dipanaskan selama 30 menit pada suhu $50^{\circ} \mathrm{C}$. Campuran didinginkan dan ditambahkan $8 \mathrm{~mL}$ larutan $\mathrm{KOH} 1 \mathrm{~N}$. Absorbansinya ditera pada panjang gelombang $480 \mathrm{~nm}$ (kuning). Persentase karbonil dihitung menggunakan rumus tersebut di bawah.

$$
\% \text { karbonil }=\frac{\mathrm{Xx} \mathrm{fp}}{\mathrm{mg} \mathrm{sampel}} \times 100 \%
$$

\section{Analisis Statistik}

Penelitian menggunakan satu faktor yaitu konsentrasi maltodekstrin dalam larutan asap cair. Taraf faktor yang digunakan yaitu F1, F2 dan F3 yang masingmasing adalah TPT $15 \%$, TPT $20 \%$ dan TPT $25 \%$. Data hasil pengamatan laboratorium diolah statistik menggunakan ANOVA oneway melalui program SPSS 16.0. Uji lanjut yang digunakan adalah DMRT dengan taraf kepercayaan $95 \%$.

\section{HASIL DAN PEMBAHASAN}

\section{Total Fenol}

Senyawa fenol pada asap cair dihasilkan oleh disintegrasi kandungan lignin pada bahan baku. Semakin tinggi kandungan lignin maka semakin tinggi pula kandungan fenol (Budaraga et al., 2016). Senyawa fenol menyediakan karakteristik aromatik, antioksidan, antimikroba dari asap cair (Saloko et al., 2013). Menurut Jeong et al. (2020), kapasitas antioksidan lebih berhubungan positif dengan senyawa fenol daripada senyawa flavonoid. Mikrokapsul fenol yang berasal dari limbah lemon (kulit, biji dan ampas) telah terbukti dapat bersifat mencegah oksidasi dan bersifat sebagai antimikroba pada produk mayonaise selama penyimpanan (Shaygannia et al., 2021)

Senyawa fenol dalam mikrokapsul asap cair memiliki aktivitas antimikroba yaitu menurunkan jumlah Total Plate Count (TPC) pada steak ikan cakalang yang 
disimpan pada suhu ruang selama 6 jam dibandingkan steak ikan cakalang tanpa perlakuan mikrokapsul asap cair (Kurniasih dkk., 2016). Tahu putih yang diberi penambahan mikrokapsul asap cair 2\% memiliki peningkatan Total Plate Count paling rendah dengan nilai slope 0,0531 jika dibandingkan tahu putih tanpa perlakuan mikrokapsul asap cair dengan nilai slope 0,2693 (Andiana dkk, 2019). Kadar total fenol mikrokapsul asap cair hasil percobaan disajikan pada Tabel 1 .

Tabel 1. Total fenol mikrokapsul asap cair dengan bahan penyalut maltodekstrin

\begin{tabular}{ccc}
\hline No & Sampel (\%) & Kadar total fenol (\%) \\
\hline 1 & TPT 15 & $6,25 \mathrm{~b}$ \\
2 & TPT 20 & $2,85 \mathrm{a}$ \\
3 & TPT 25 & $2,60 \mathrm{a}$ \\
\hline Keterangan : Angka yang diikuti huruf yang sama pada satu kolom tidak \\
& berbeda nyata menurut uji lanjut DMRT pada taraf nyata \\
& 95\%. TPT 15\%: & total padatan terlarut larutan \\
& mikropartikel asap cair 15\%. TPT 20\%: total padatan \\
& terlarut larutan mikropartikel asap cair 20 \%. TPT \\
& 25\%: total padatan terlarut larutan mikropartikel \\
& asap cair 25\%.
\end{tabular}

Kadar total fenol mikrokapsul asap cair pada TPT $15 \%, 20 \%, 25 \%$ berturut-turut adalah sebesar 6,25 \%, 2,85\% dan 2,6\% (Tabel 1). Semakin tinggi padatan terlarut maka kadar fenol semakin menurun. Hal ini senada dengan penelitian Syah et al. (2015) yang menyatakan bahwa total padatan terlarut yang tinggi yang disebabkan oleh tingginya konsentrasi maltodekstrin dari beras pecah, dapat menyebabkan kandungan total fenol mikrokapsul asap cair menjadi rendah. Yudhistira \& Choiriyah (2015) yang melakukan penelitian enkapsulasi ekstrak antosianin rosella menyatakan bahwa semakin tinggi padatan terlarut maka akan menurunkan kadar senyawa bioaktif suatu produk mikrokapsul atau nanokapsul. Yibin et al. (2017) juga menyebutkan bahwa tingginya konsentrasi bahan penyalut dapat menurunkan konsentrasi senyawa fenol pada mikrokapsul ekstrak plum. Menurut penelitian Loksuwan (2006) dan Syah et al (2015), tingginya konsentrasi maltodekstrin dapat meningkatkan kelarutan mikrokapsul sehingga mempercepat waktu phenol release. Berdasarkan kadar total fenol perlakuan TPT 15\% dapat memberikan efek antioksidan dan antimikroba yang paling tinggi serta berpotensi memiliki kemampuan mengawetkan produk makanan yang lebih lama.

\section{Total Asam}

Umumnya asap cair memiliki karakteristik asam dengan $\mathrm{pH}$ 1,5-5,5 dimana kandungan asam tersebut ditentukan oleh bahan asal, langkah proses pembuatan dan pemurnian (Montazeri et al., 2012). Diatmika et al. (2019) melaporkan bahwa proses pirolisis menyebabkan dekomposisi hemiselulosa sehingga terbentuk asam-asam seperti asam asetat pada asap cair. Jenis asam yang terdapat pada asap cair yaitu asam asetat, format, butirat, propionat, valerat dan isokaproat. Asam-asam tersebut dapat menurunkan pH (Khamidah dkk., 2019) dan berpengaruh terhadap flavor dan umur simpan makanan (Darmadji et al., 2012). Senyawa asam pada mikrokapsul asap cair juga berkontribusi terhadap penurunan TPC steak ikan cakalang selama penyimpanan 6 jam dibandingkan steak ikan cakalang tanpa perlakuan mikrokapsul asap cair (Kurniasih dkk., 2016).

Hasil analisis total asam pada mikrokapsul asap cair ditunjukkan pada Tabel 2. Berdasarkan Tabel 2 total asam mikrokapsul asap cair dengan penambahan maltodekstrin hingga TPT 15\%, 20\%, dan 25\% berturut-turut adalah 6,00\%; 9,70\%; dan 10,76\%. Semakin tinggi persen penambahan maltodekstrin, total asam mikrokapsul asap cair semakin tinggi. Maltodekstrin yang digunakan masih mempunyai residu asam yang didapatkan sewaktu pembuatan maltodekstrin itu sendiri yang berkontribusi terhadap tingginya total asam produk powder (Yuliwati \&Susanto, 2015).

Tabel 2. Total asam mikrokapsul asap cair

\begin{tabular}{ccc}
\hline No & Sampel & Kadar total asam (\%) \\
\hline 1 & TPT 15\% & $6,00 \mathrm{a}$ \\
2 & TPT 20\% & $9,70 \mathrm{~b}$ \\
3 & TPT 25\% & $10,76 \mathrm{~b}$ \\
\hline
\end{tabular}

Keterangan : Notasi huruf yang berbeda di belakang angka menunjukkan bahwa sampel berbeda nyata secara statistik dengan tingkat kepercayaan 95\%. TPT 15\%: total padatan terlarut larutan mikropartikel asap cair $15 \%$. TPT 20\%: total padatan terlarut larutan mikropartikel asap cair $20 \%$. TPT 25\%: total padatan terlarut larutan mikropartikel asap cair $25 \%$.

\section{Total Karbonil}

Warna coklat gelap pada asap cair diakibatkan oleh kandungan senyawa karbonil. Senyawa karbonil didapatkan dari degradasi selulosa (Budaraga et al., 2016). Asap cair dengan konsentrasi senyawa karbonil yang tinggi digunakan sebagai pembentuk warna coklat (browning agent) pada bahan pangan (Montazeri et al., 2012) dan pengawet (Widiastuti dkk., 2019). Kadar karbonil mikrokapsul asap cair ditunjukkan oleh Tabel 3. Kadar karbonil mikrokapsul asap cair dengan TPT 15\%, 20\%, dan $25 \%$ masing-masing sebesar $4,69 \%, 3,78 \%$, dan $4,08 \%$ 
(Tabel 3). Penambahan maltodekstrin sampai dengan TPT larutan mikropartikel 15, 20, dan $25 \%$ tidak berpengaruh terhadap kadar karbonil asap cair.

Tabel 3. Total karbonil mikrokapsul asap cair

\begin{tabular}{ccc}
\hline No & Sampel & Kadar total karbonil (\%) \\
\hline 1 & TPT 15\% & $4,69 \mathrm{a}$ \\
2 & TPT 20\% & $3,78 \mathrm{a}$ \\
3 & TPT 25\% & $4,08 \mathrm{a}$ \\
\hline
\end{tabular}

Keterangan : Notasi huruf yang berbeda di belakang angka menunjukkan bahwa sampel berbeda nyata secara statistik dengan tingkat kepercayaan 95\%. TPT 15\%: total padatan terlarut larutan mikropartikel asap cair 15\%. TPT 20\%: total padatan terlarut larutan mikropartikel asap cair $20 \%$. TPT 25\%: total padatan terlarut larutan mikropartikel asap cair $25 \%$.

Nilai total karbonil pada penelitian ini lebih rendah jika dibandingkan dengan penelitian Kurniasih dkk. (2016) tentang nanokapsul asap cair dengan kandungan total karbonil sebesar 9,76\%. Hal ini disebabkan asal tempurung kelapa, proses pembuatan asap cair dan bahan penyalut yang digunakan berbeda.

\section{SIMPULAN}

Kesimpulan dari penelitian ini sebagai berikut kadar fenol tertinggi adalah mikrokapsul asap cair dengan enkapsulan maltodekstrin sampai TPT 15\%. Penambahan maltodekstrin sebagai enkapsulan tidak berpengaruh pada kadar total karbonil mikrokapsul asap cair. Penambahan persen maltodekstrin dapat meningkatkan kadar total asam pada mikrokapsul asap cair. Proses enkapsulasi asap cair terbaik dapat dilakukan menggunakan bahan penyalut maltodekstrin dengan TPT 15\% karena memiliki kadar total fenol tertinggi yang berkontribusi terhadap sifat antioksidan dan antimikroba.

\section{DAFTAR PUSTAKA}

Andiana, A, N Aini, dan K Karseno. 2019. Produk enkapsulasi asap cair sekam padi dan aplikasinya untuk mengawetkan tahu putih. Jurnal Agroteknologi. 13(2): 180-194.

Ariestya, DI, F Swastawati, and E Susanto. 2016. Antimicrobial activity of microencapsulation liquid smoke on tilapia (Oreochromis niloticus) meat for preservatives in cold storage $\left( \pm 5^{\circ} \mathrm{C}\right)$. Aquatic Procedia. 7: 19-27.

Budaraga, K, MY Arnim, and U Bulanin. 2016. Liquid smoke production quality from raw materials variation and different pyrolysis temperature. International Journal on Advanced Science, Engineering and Information Technology. 6(3): 306-315.

Darmadji, P. 2002. Optimasi proses pembuatan tepung asap. Agritech. 22(4): 172-177.

Darmadji, P, S Saloko, B Setiaji, dan Y Pranoto. 2012. Inovasi prototipe produk nanoenkapsulasi biopreservatif asap cair sebagai pengawet pangan alami. Prosiding Insinas.

Desvita, H, M Faisal, Mahidin, and Suhendrayatna. 2020. Preservation of meatballs with edible coating of chitosan dissolved in rice hull-based liquid smoke. Heliyon. 6(10): 1-10.

Diatmika, IG, PKD Kencana, dan G Arda. 2019. Karakteristik asap cair batang bambu tabah (Gigantochloa nigrociliata) yang dipirolisis pada suhu yang berbeda. Jurnal BETA (Biosistem Dan Teknik Pertanian). 7(2): 271277.

Jeong HR, HS Cho,YS Cho, and DO Kim. 2020. Changes in phenolics, soluble solids, vitamin $\mathrm{C}$, and antioxidant capacity of various cultivars of hardy kiwifruits during cold storage. Food Science and Biotechnology. 29(12): 17631770 .

Khamidah, S, F Swastawati, dan Romadhon. 2019. Efek perbedaan lama perendaman asap cair kulit durian terhadap kualitas ikan manyung (Arius thalassinus) asap. Jurnal Ilmu dan Teknologi Perikanan. 1(1): 7-13.

Kurniasih, RA, P Darmadj, dan Y Pranoto. 2016. Pemanfaatan asap cair terenkapsulasi maltodesktrin-kitosan sebagai pengawet ikan cakalang (Katsuwonus pelamis ). Jurnal Teknologi Hasil Pertanian. 9(1): 9-16.

Kusumawati, I, dan F Zuhro. 2019. Dampak sosialisasi aplikasi asap cair organik terhadap pengendalian bulai tanaman jagung pada kelompok tani karang asem indah Kabupaten Situbondo. BIO-CONS, Jurnal Biologi \& Konservasi. 1(1): 28-34.

Montazeri, N, ACM Oliveira, B Himelbloom, MB Leigh, and CA Crapo. 2012. Chemical characterization of commercial liquid smoke products. Food Science and Nutrition. 1(1): 102-115.

Mugiastuti, E, dan A Manan. 2009. Pemanfaatan asap cair untuk mengendalikan Fusarium oxysporum dan Meloidogyne spp. Jurnal Pembangunan Pedesaan. 9(1): 43-49. 
Naufalin, R, and HS Rukmini. 2016. Antioxidant activity and physicochemical properties of Nicolaia speciosa flower extract. Agriculture and Agricultural Science Procedia. 9: 297-303.

Oramahi, HA, and F Diba. 2013. Maximizing the production of liquid smoke from bark of durio by studying its potential compounds. Procedia Environmental Sciences. 17:60-69.

Petzold, G, MP Gianelli, G Bugueño, F Celan, C Pavez, and P Orellana. 2014. Encapsulation of liquid smoke flavoring in $\mathrm{Ca}$-alginate and $\mathrm{Ca}-$ alginate-chitosan beads. Journal of Food Science and Technology. 51(1): 183-190.

Poluakan, OA, HA Dien, dan FG Ijong. 2015. Mutu mikrobiologis bakso ikan yang direndam asap cair, dikemas vakum, dipasteurisasi, dan disimpan pada suhu dingin. Jurnal Media Teknologi Hasil Perikanan. 3(2): 41-44.

Saloko, S, P Darmadji, B Setiaji, Y Pranoto, and AK Anal. 2013. Encapsulation of coconut shell liquid smoke in chitosan-maltodextrin based nanoparticles. International Food Research Journal. 20(3): 1269-1276.

Savikin, K, N Nasti, T Jankovi, D Bigovi, B Milicevi, S Vidovi,

N Menkovi, and J Vladi. 2021. Effect of type and concentration of carrier material on the encapsulation of pomegranate peel using spray drying method. Foods. 10(1968): 1-11.

Shaygannia S, MR Eshaghi, M Fazel, and M Hashemiravan. 2021. the effect of microencapsulation of phenolic compounds from lemon waste by persian and basil seed gums on the chemical and microbiological properties of mayonnaise. Preventive Nutrion and Food Science. 26(1):82-91. doi: 10.3746/pnf.2021.26.1.82. PMID: 33859963; PMCID: PMC8027048.

Sokamte-Tegang, A, PD Mbougueng, NM Sachindra, NF Nodem, and TL Ngoune. 2020. Characterization of volatile compounds of liquid smoke flavourings from some tropical hardwoods. Scientific African. 8(1): 23-30.
Syah, IT, P Darmadji, and Y Pranoto. 2015. Microencapsulation of refined liquid smoke using maltodextrin produced from broken rice starch. Journal of Food Processing and Preservation. 40(3):30-37.

Talib, A, A Husen, dan S Gunawan. 2020. Karakteristik uji organoleptik ikan cakalang asap dengan menggunakan asap cair dari tempurung kelapa, sabut kelapa dan kayu mangrove. Jurnal Agribisnis Perikanan. 13(1): 69-75.

Valø, T, AN Jakobsen, and J Lerfall. 2020. The use of atomized purified condensed smoke (PCS) in cold-smoke processing of Atlantic salmoneffects on quality and microbiological stability of a lightly salted product. Food Control. 112:155-162.

Widiastuti, I, RM Herpandi, dan NY Arrahmi. 2019. Karakteristik sotong (Sepia recurvirostra) asap yang diolah dengan berbagai konsentrasi asap cair. Jurnal Pengolahan Hasil Perikanan Indonesia. 22(1): 24-32.

Yibin, LO, T Baosha, J Chen, and LAO Pufu. 2017. Microencapsulation of plum (Prunus salicina Lindl.) phenolics by spray drying technology and storage stability. Food Science and Technology. 38(3): 530-536.

Yuliwaty, ST, dan WH Susanto. Pengaruh lama pengeringan dan konsentrasi maltodekstrin terhadap karakteristik fisik kimia dan organoleptik minuman instan daun mengkudu (Morinda citrifolia L). Jurnal Pangan dan Agroindustri. 3(1): 1-9.

Yudhistira, B, and NA Choiriyah. Physical and chemical properties of roselle extract nanocapsule with inulin, chitosan and maltodextrin as encapsulant. Food Research. 5(6): $172-177$

Zuanif, V, dan R Despita. 2019. Uji kemampuan asap cair secara in vitro dan in vivo untuk penyakit antraknosa (Colletotrichum capsici) pada tanaman cabai (Capsicum annum L). Jurnal Agriekstensia. 18 (2): 160-169. 